\title{
Short-term variation in plasma mitotane levels confirms the importance of trough level monitoring
}

\author{
T M A Kerkhofs', L J J Derijks², M H T Ettaieb', E M W Eekhoff ${ }^{3}$, C Neef ${ }^{4,5}$, \\ H Gelderblom ${ }^{6}$, J den Hartigh ${ }^{7}$, H J Guchelaar' ${ }^{7}$ and H R Haak ${ }^{1,5,8}$
}

\begin{abstract}
1Department of Internal Medicine, Máxima Medical Center, Ds. Th. Fliednerstraat 1, Eindhoven/Veldhoven 5631, The Netherlands, ${ }^{2}$ Department of Clinical Pharmacology, Máxima Medical Center, Eindhoven/Veldhoven, The Netherlands, ${ }^{3}$ Section Endocrinology, Department of Internal Medicine, VU Medical Center, Vrije Universiteit Amsterdam, Amsterdam, The Netherlands, ${ }^{4}$ Department of Clinical Pharmacy and Toxicology, Maastricht University Medical Center+, Maastricht, The Netherlands, ${ }^{5}$ Department of Health Services Research and CAPHRI School for Public Health and Primary Care, Maastricht University, Maastricht, The Netherlands, Departments of ${ }^{6} \mathrm{Clinical}$ Oncology and ${ }^{7}$ Clinical Pharmacy and Toxicology, Leiden University Medical Center, Leiden, The Netherlands and ${ }^{8}$ Division of General Internal Medicine, Department of Internal Medicine, Maastricht University Medical Centre+، Maastricht, The Netherlands
\end{abstract}

\author{
Correspondence \\ should be addressed \\ to T M A Kerkhofs \\ Email \\ T.Kerkhofs@mmc.nl
}

\begin{abstract}
Objective: Mitotane is the drug of choice in patients with adrenocortical carcinoma. The anti-neoplastic effect is correlated with mitotane plasma levels, which render it crucial to reach and maintain the concentration above $14 \mathrm{mg} / \mathrm{l}$. However, mitotane pharmacokinetics is poorly understood. The aim of this study was to investigate the variation in plasma mitotane levels during the day and the influence of a single morning dose.

Design: A prospective case-control study was conducted to investigate the variation in plasma mitotane levels. Methods: Patients who had been treated for at least 24 weeks and had reached the therapeutic plasma level ( $14 \mathrm{mg} / \mathrm{l})$ at least once were eligible. In the first group, mitotane levels were determined hourly for the duration of $8 \mathrm{~h}$ after administration of a single morning dose. In the second group, mitotane levels were assessed similarly without administration of a morning dose.

Results: Ten patients were included in this study, and three patients participated in both groups. Median plasma level at baseline was $16.2 \mathrm{mg} / \mathrm{l}$ (range 11.3-23.3 mg/l) in the first group $(n=7)$ and $17.0 \mathrm{mg} / \mathrm{l}(13.7-23.8)$ in the second group $(n=6)$. Plasma levels displayed a median increase compared with baseline of $24 \%$ (range $6-42 \%$ ) at $t=4$ after morning dose and a change of $13 \%$ (range -14 to $33 \%)$ at $t=4$ without morning dose $(P=0.02)$.

Conclusion: A substantial increase in mitotane plasma levels was observed in steady-state patients within a period of $8 \mathrm{~h}$ after morning dosing. Without morning dose, mitotane curves showed a variable profile throughout the day. This implies that random sampling could yield incidentally high levels. For this reason, we recommend early-morning trough sampling as standard management in monitoring mitotane treatment.
\end{abstract}

\section{Introduction}

The adrenolytic drug mitotane (2,2(1-chlorophenyl,2chlorophenyl)1,1-dichloroethane [o, $\left.\left.\mathrm{p}^{\prime} \mathrm{DDD}\right]\right)$ is registered for treatment of adrenocortical carcinoma (ACC) $(1,2)$. Mitotane affects the adrenal steroid synthesis that results in diminished cortisol secretion, but the exact mechanism of action is unknown (3). It also exerts an anti-neoplastic effect on ACCs, which is the main indication for treatment in ACC patients. The anti-steroidogenic effect is a (c) 2014 European Society of Endocrinology Printed in Great Britain
Published by Bioscientifica Ltd. 
fortuitous side effect in patients suffering from hypercortisolism due to a functional ACC.

In addition to the well-established use of mitotane in irresectable and metastasized ACC, there is increasing evidence that adjuvant mitotane after radical resection of the primary tumor increases recurrence-free survival $(4,5,6)$. In anticipation of prospective confirmation, the international consensus is to recommend mitotane in patients with high risk of recurrence, i.e. after irradical resection and/or ki-67 index $>10 \%$ (7).

The anti-neoplastic effect appears to be correlated with plasma levels: several studies have reported an objective response in patients whose plasma trough levels were above $14 \mathrm{mg} / \mathrm{l}(8,9,10)$. Although this does not rule out the possibility of response at lower plasma levels, a major goal during mitotane therapy is to reach and maintain plasma levels above $14 \mathrm{mg} / \mathrm{l}$. In order to limit drug toxicity, $20 \mathrm{mg} / \mathrm{l}$ is considered the upper limit of the therapeutic window (9). In general, the build-up of plasma levels is slow, taking 3-4 months on average, but interindividual differences are large $(11,12,13)$. As knowledge on mitotane pharmacokinetics is sparse, current dosing regimens are based on clinical experience and adjusted according to plasma levels and tolerability. In some hospitals including our own, it is a common practice to monitor mitotane plasma levels by performing trough measurements, i.e. at least $12 \mathrm{~h}$ after the last dose. In other centers, random measurements throughout the day are accepted. Owing to mitotane's extremely long half-life of 18-159 days, it is hypothesized that plasma levels show little variation between doses, and trough sampling is not necessary. However, this has never been studied in patients who reached steady state (14). The aim of this study was to investigate the variation of plasma mitotane levels during the day and the influence of a single morning dose.

\section{Subjects and methods}

The variation in mitotane plasma levels was prospectively investigated in ACC patients who had been treated for at least 24 weeks and who had reached the therapeutic plasma level ( $>14 \mathrm{mg} / \mathrm{l})$ at least once. The study protocol was approved by the medical research ethics committee in Máxima Medical Center and all patients signed informed consent.

In the first group, patients took their regular morning dose (RMD) of mitotane with a minimum of $1000 \mathrm{mg}$ (range $1000-1500 \mathrm{mg}$ ) orally at baseline $(0800 \mathrm{~h})$. Two patients (ID 4 and 6) were on a dosing regimen with no or $500 \mathrm{mg}$ mitotane at breakfast. In these patients, the total daily dose was administered at baseline during the study (1000 and $1500 \mathrm{mg}$ respectively). The time since prior dosing was at least $12 \mathrm{~h}$. Mitotane plasma levels were determined at baseline and hourly for the duration of $8 \mathrm{~h}$. Patients did not take other mitotane doses during this time. Concomitant medication was allowed and registered. All patients were served the same breakfast (at $0800 \mathrm{~h}$, after blood withdrawal for baseline measurement) and lunch (at $1200 \mathrm{~h}$, after $t=4$ measurement) to rule out the influence of food on drug absorption as a confounding factor.

In the second group, mitotane was not administered on the day of study (no regular morning dose (nRMD)), but patients had taken their regular doses the day before. Determination of mitotane plasma levels and food intake was identical to the first group. Patients did not engage in strenuous physical activities and spent the day mostly reading or watching television.

Liver enzymes (gamma-glutamyltransferase $(\gamma$-GT), aspartate aminotransferase (ASAT), alanine aminotransferase (ALAT)), lactate dehydrogenase (LDH), alkaline phosphatase, and serum creatinine were analyzed at baseline.

\section{Measurement of plasma levels}

Mitotane plasma concentrations were determined by high-performance liquid chromatography (HPLC) with u.v. detection at Atlanbio laboratory (Saint-Nazaire, France) using the Lysosafe service offered by HRA Pharma (Paris, France). The HPLC assay is calibrated and verified every 2 months. The method is validated with an accepted variability of $\pm 15 \%$ on concentration values. The mean intra-assay coefficient of variation (CV) was $3.7 \%$ and mean inter-assay $\mathrm{CV}$ was $2.7 \%$ in test runs carried out during this study with a validation sample concentration of $20 \mathrm{mg} / \mathrm{l}$. Since July 2013, a gas chromatography/mass spectrometry assay is used for mitotane plasma concentration measurement. Mean intra-assay $\mathrm{CV}$ was $2.7 \%$ and mean inter-assay $\mathrm{CV}$ was $2.0 \%$ in test runs carried out with a quality control sample concentration of $25 \mathrm{mg} / \mathrm{l}$. Previous research determined a good agreement between both assays (15). As medium to high mitotane levels were anticipated, a change in plasma levels $\geq 1.0 \mathrm{mg} / \mathrm{l}$ was considered clinically significant in this study. This translates to a $\mathrm{CV}$ of $5 \%$, given a mean concentration of $20 \mathrm{mg} / \mathrm{l}$ (data provided by HRA Pharma). 


\section{Statistical analysis}

Main parameter in this study was the variation of mitotane plasma levels during the day. All individual measurements were displayed. In addition, median change from baseline was calculated per group and displayed. The non-parametric Mann-Whitney $U$ test was used to analyze the median change in plasma levels between both groups.

Data management and statistical analyses were performed using Prism 6.0 (Graphpad Software, La Jolla, CA, USA) and SPSS 19.0 (IBM, Armonk, NY, USA).

\section{Results}

Ten patients were analyzed; there were eight women and two men (Table 1). Three patients (ID 11, 12, and 13) participated in both the RMD and the nRMD group, resulting in 13 individual mitotane curves. Time between both study days for patients who were analyzed twice was 81,65 , and 62 weeks respectively.

The median time since the start of mitotane therapy was 54 weeks (range 29-114 weeks) in the RMD group and 80 weeks (46-121 weeks) in the nRMD group. Median BMI was $28.4 \mathrm{~kg} / \mathrm{m}^{2}\left(21.1-36.8 \mathrm{~kg} / \mathrm{m}^{2}\right)$ in the first group and 27.6 $\left(20.8-36.4 \mathrm{~kg} / \mathrm{m}^{2}\right)$ in the second. Four patients used a proton pump inhibitor during the study day (ID 1, 2, 4, and 13) and one patient used an $\mathrm{H} 2$ receptor antagonist (ID 3 ).
Three patients had mitotane concentrations $<14 \mathrm{mg} / \mathrm{l}$ at baseline and all patients reached this threshold at some point during the day they were studied (Figs $1 \mathrm{~A}$ and $2 \mathrm{~A}$ ). The median plasma level at baseline was $16.2 \mathrm{mg} / \mathrm{l}$ (range $11.3-23.3 \mathrm{mg} / \mathrm{l}$ ) in the RMD group and $17.0 \mathrm{mg} / \mathrm{l}$ (range 13.7-23.8) in the nRMD group. Among patients who did take a morning dose, individual maximum plasma concentrations were reached after $2(n=1), 3(n=1), 4$ $(n=2), 5(n=2)$ or $7 \mathrm{~h}(n=1)$. In five out of six patients, without morning dose, mitotane plasma levels increased during the day as well: maximum levels were reached after $4(n=2), 6(n=2)$, or $8 \mathrm{~h}(n=1)$. One patient demonstrated the maximum level at baseline (Patient 11).

In the RMD group, the median change in the plasma level compared with baseline was $+3 \%$ at $t=1$ (range -8 to $15 \%$ ), $+24 \%$ at $t=4$ (range $6-42 \%$ ) and $+3 \%$ at $t=8$ (range -10 to $19 \%$, Fig. 1B). The greatest individual increment observed was $54 \%$ between $t=0$ and $t=5$ (Patient 7).

In the nRMD group, the median change in the plasma level compared with baseline was $-2 \%$ at $t=1$ (range -5 to $4 \%$ ), $+13 \%$ at $t=4$ (range -14 to $33 \%$ ), and $-2 \%$ at $t=8$ (range -8 to $21 \%$, Fig. $2 \mathrm{~B}$ ). The greatest individual increment observed was $26 \%$ between $t=0$ and $t=5$ (Patient 8). The median change in the mitotane plasma level at $t=4$ was significantly different between both groups ( $P=0.02)$.

Table 1 Demographic and mitotane dosing characteristics of patients in the maintenance phase of mitotane treatment.

\begin{tabular}{|c|c|c|c|c|c|c|c|}
\hline Patient ID & Sex & BMI $\left(\mathrm{kg} / \mathrm{m}^{2}\right)$ & $\begin{array}{l}\text { Duration of mito- } \\
\text { tane treatment } \\
\text { (weeks) }\end{array}$ & $\begin{array}{l}\text { Normal dosing } \\
\text { regimen }(\mathrm{mg})\end{array}$ & $\begin{array}{c}\text { Dose at baseline } \\
(\mathrm{mg})\end{array}$ & $\begin{array}{l}\text { Last dose before } \\
\text { study day (mg) }\end{array}$ & $\begin{array}{c}\text { Time since last } \\
\text { dose }(\mathrm{h})\end{array}$ \\
\hline \multicolumn{8}{|c|}{ With morning dose } \\
\hline 1 & $\mathrm{~F}$ & 23.9 & 114 & 1500-500-1000 & 1500 & 1000 & 13 \\
\hline 2 & $\mathrm{~F}$ & 30.9 & 81 & $1000-0-500$ & 1000 & 500 & 14 \\
\hline 3 & $\mathrm{M}$ & 25 & 54 & 1000-1000-1000 & 1000 & 1000 & 12 \\
\hline 4 & $\mathrm{~F}$ & 32.4 & 40 & $500-500-500^{a}$ & 1500 & 500 & 15 \\
\hline 5 & $\mathrm{M}$ & 21.1 & 29 & $1500-1000-1500$ & 1500 & 1500 & 12 \\
\hline 6 & $\mathrm{~F}$ & 28.4 & 86 & $0-500-500^{a}$ & 1000 & 500 & 13 \\
\hline 7 & $\mathrm{~F}$ & 36.8 & 35 & $1500-1500-2000$ & 1500 & 2000 & 15 \\
\hline Median & & 28.4 & 54 & & 1500 & 1000 & 13 \\
\hline Range & & $21.1-36.8$ & $29-114$ & & $1000-1500$ & $500-2000$ & $12-15$ \\
\hline \multicolumn{8}{|c|}{ Without morning dose } \\
\hline 8 & $\mathrm{~F}$ & 26.1 & 57 & $1000-500-500$ & N/A & 500 & 13 \\
\hline 9 & $\mathrm{~F}$ & 25.6 & 46 & $500-0-500$ & N/A & 500 & 14 \\
\hline 10 & $\mathrm{~F}$ & 29.1 & 66 & $500-500-500$ & N/A & 500 & 13 \\
\hline $11(5)$ & $\mathrm{M}$ & 20.8 & 94 & $1000-1000-1000$ & N/A & 1000 & 10 \\
\hline $12(7)$ & $\mathrm{F}$ & 36.4 & 97 & $500-500-500$ & N/A & 500 & 15 \\
\hline $13(4)$ & $\mathrm{F}$ & 30.8 & 121 & $500-0-500$ & N/A & 500 & 13 \\
\hline Median & & 27.6 & 80 & & N/A & 500 & 13 \\
\hline Range & & $20.8-36.4$ & $46-121$ & & N/A & 500-1000 & $10-15$ \\
\hline
\end{tabular}

${ }^{a}$ Two patients were on a dosing regimen with no or a single tablet of mitotane at breakfast. In these patients, the total dose was administered at baseline during the study. 

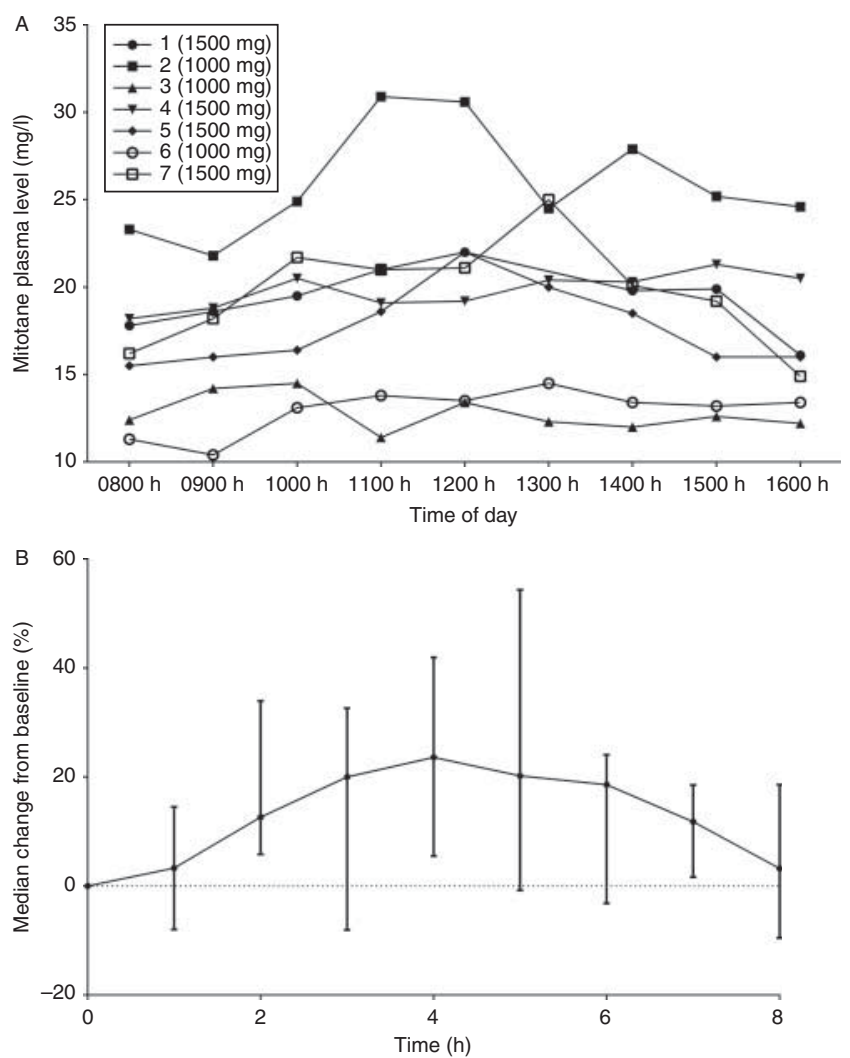

\section{Figure 1}

(A) Individual variations in mitotane plasma levels after morning dose in patients 1-7. (B) Median change from baseline mitotane plasma level after morning dose in seven patients.

In all patients, elevated $\gamma$-GT levels were observed and the median level was $234 \mathrm{U} / 1$ (120-430) in the first group and $80 \mathrm{U} / \mathrm{l}$ (63-572) in the second group (Table 2). Other laboratory investigations did not indicate impaired liver or kidney function in any of the patients.

\section{Discussion}

Our results show a median mitotane plasma level increment of $24 \%$ at $4 \mathrm{~h}$ after a single morning dose. This implies that random sampling could yield significantly higher levels compared with trough sampling. When a morning dose is skipped, the mitotane curve displays a variable profile with significant increments during the day in half of the patients studied. The variability is greater than expected, given the extremely long half-life of the drug. Physicians should be aware of the variability, especially since the lower limit of the therapeutic window $(14 \mathrm{mg} / \mathrm{l})$ was established based on research with trough levels $(8,9)$. For these reasons, we recommend trough sampling as standard management in monitoring mitotane treatment. Early morning appears to be the most suitable moment to assess trough levels.

Our results illustrate that random plasma level sampling could cause inappropriate dosing adjustments. For example, if Patient 5 would have had a routine mitotane assessment in outpatient setting at $1200 \mathrm{~h}$, it is likely that the dose would have been reduced based on the result of $22 \mathrm{mg} / \mathrm{l}$. The trough level of $15 \mathrm{mg} / \mathrm{l}$ is only within the therapeutic window, which would justify dose continuation.

To our knowledge, the variation in mitotane levels after a single dose has never been studied in patients who are at steady state. In a study conducted from 1981, plasma levels in mitotane-naïve patients were evaluated after a standard dose was given in various vehicles (tablets, granules, emulsion, chocolate, and milk) (14). Mean plasma levels measured at 5 and $10 \mathrm{~h}$ after ingestion of $2000 \mathrm{mg}$ (as commercially available tablets) were $1.8 \pm 1.1$ and $1.5 \pm 1.0 \mathrm{mg} / \mathrm{l}$ respectively. The concentration-time
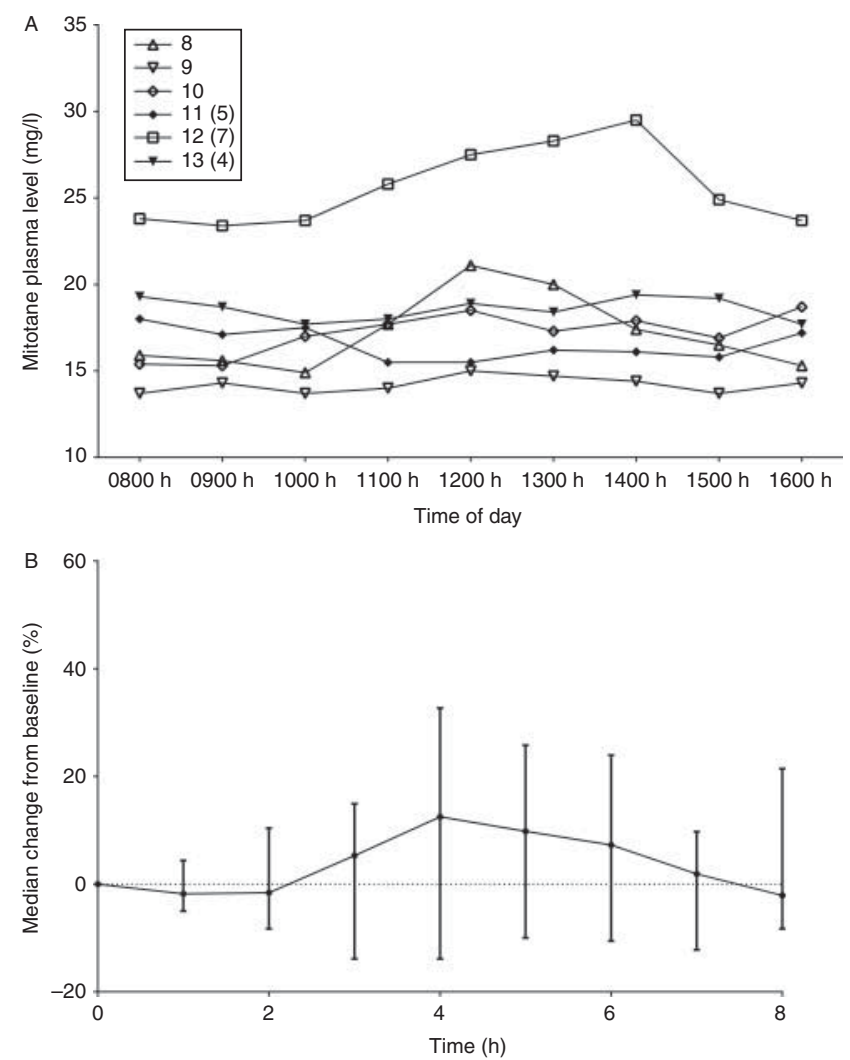

Figure 2

(A) Individual variations in mitotane plasma levels without morning dose in patients 8-13. (B) Median change from baseline mitotane plasma level without morning dose in six patients. 
Table 2 Results from baseline laboratory investigations in patients at steady state of mitotane treatment.

\begin{tabular}{lc}
\hline \multicolumn{1}{l}{ Patient ID } & $\gamma$-GT (U/I) \\
\cline { 1 - 2 } $\begin{array}{lc}\text { With morning dose } \\
1\end{array}$ & 430 \\
2 & 120 \\
3 & 192 \\
4 & 234 \\
5 & 122 \\
6 & 295 \\
7 & 375 \\
Median & 234 \\
Range & $120-430$ \\
Without morning dose & \\
8 & 63 \\
9 & 572 \\
10 & 65 \\
11 (5) & 91 \\
12 (7) & 68 \\
13 (4) & 156 \\
Median & 80 \\
Range & $63-572$ \\
\hline
\end{tabular}

\begin{tabular}{c}
\hline ASAT (U/I) \\
\hline 21 \\
16 \\
28 \\
40 \\
25 \\
12 \\
116 \\
25 \\
$12-116$ \\
19 \\
34 \\
28 \\
23 \\
38 \\
19 \\
26 \\
$19-38$ \\
\hline
\end{tabular}

\begin{tabular}{c}
\hline ALAT (U/I) \\
\hline 17 \\
16 \\
26 \\
60 \\
15 \\
9 \\
75 \\
17 \\
$9-75$ \\
11 \\
85 \\
13 \\
15 \\
22 \\
20 \\
18 \\
$11-85$ \\
\hline
\end{tabular}

\begin{tabular}{c}
\hline LDH $(\mathrm{U} / \mathrm{I})$ \\
\hline 220 \\
170 \\
200 \\
230 \\
200 \\
130 \\
280 \\
200 \\
$130-280$ \\
220 \\
170 \\
210 \\
170 \\
210 \\
170 \\
190 \\
$170-220$ \\
\hline
\end{tabular}

\begin{tabular}{c}
\hline Alk. Phos. (U/l) \\
\hline 77 \\
100 \\
87 \\
208 \\
50 \\
51 \\
102 \\
87 \\
$50-208$
\end{tabular}

Creat. $(\mu \mathrm{mol} / \mathrm{l})$

$\gamma$-GT, gamma-glutamyltransferase; ASAT, aspartate aminotransferase; ALAT, alanine aminotransferase; LDH, lactate dehydrogenase; Alk. Phos., alkaline phosphatase; Creat, creatinine.

curves showed more than one maximum, similar to our observations in five out of seven patients. In this study, the observed difference between both groups in plasma level increment at $t=4$ must be caused by administration of the morning dose. However, five out of six patients from the nRMD group displayed an increase in the mitotane plasma level during the day despite the absence of a morning dose. In three of these patients, the increase constituted $>20 \%$ of the baseline level. This finding cannot be explained by delayed gastrointestinal absorption, given the time interval of $\sim 17 \mathrm{~h}$ since the last dose. In addition, enterohepatic reabsorption seems unlikely as previous research could not detect unmetabolized mitotane in bile (16). Therefore, we have to speculate on another explanation. Redistribution of mitotane between fatty tissues and plasma might cause fluctuation in mitotane levels. This mechanism is mainly influenced by transport in both directions, binding of mitotane to plasma lipoproteins, and metabolization into 2,4-dichlorodiphenyl acetic acid $(17,18)$. Probably, mitotane clearance has a minor impact on the plasma level. This is in accordance with the drug's known lipophilicity and earlier findings regarding the development of a pharmacokinetic model of mitotane (13). The model estimated the volume of distribution to be relatively high $(161 \pm 68 \mathrm{l} / \mathrm{kg} \mathrm{LBM})$ and clearance to be relatively low $(1.12 \pm 0.41 \mathrm{l} / \mathrm{h})$. Moreover, previous observations of fatty tissue concentrations that were $\sim 200$-fold higher than plasma concentrations are in accordance with this hypothesis (19). Since the time from baseline to peak variability in both groups seems to be comparable (3-5 h), the influence of food intake should be considered. As this was standardized in both groups, this study does not permit conclusions on this topic.

There was a broad distribution of plasma level increments between patients in both groups despite the standardization of food intake and daytime activities. Moreover, we could not identify a correlation between the plasma level increment and the use of a proton pump inhibitor, a hydrocortisone dose nor patient characteristics such as BMI, duration of treatment, or baseline plasma level. Genetic differences in absorption, distribution, metabolism, and excretion (ADME) genes may be crucial for explaining differences in mitotane pharmacokinetics between patients. Research has indicated that a single nucleotide polymorphism in the gene coding for the CYP2B6 enzyme was significantly associated with the mitotane level achieved after 3 and 6 months of treatment (20). Observations from that study suggest that CYP2B6 is influential on mitotane metabolism, possibly through first-pass metabolism in the intestinal mucosa. Increased levels of $\gamma$-GT are often reported in patients undergoing treatment with mitotane, but the cause is unknown. Studies carried out in patients treated adjuvantly have demonstrated that the increase is reversible (21). We could not find a satisfactory explanation for the apparent difference in $\gamma$-GT levels between both groups in this study, but we considered that this unlikely influenced our results. This study was not designed to examine the 
frequency or severity of side effects in patients with plasma levels $>20 \mathrm{mg} / \mathrm{l}$. Patients were questioned orally during the day and none reported adverse events of grade 3 or higher according to the common terminology criteria for adverse events. We speculate that incidental peaks above $20 \mathrm{mg} / \mathrm{l}$ during the day are acceptable in terms of toxicity, but that baseline levels $>20 \mathrm{mg} / \mathrm{l}$ should be avoided. At steady state, the primary aim should be to keep the baseline level above $14 \mathrm{mg} / \mathrm{l}$ with the lowest possible maintenance dose. Given the observation that a rise in mitotane plasma levels after a single dose lasts for $\sim 8 \mathrm{~h}$, we advise an administration schedule with three daily doses.

We acknowledge the limitations of our study. Intrapatient variability could influence our results as measurements were performed on 1 day per patient only. Early morning measurements might be subject to variation as well. In clinical practice, it could be considered to perform multiple early measurements shortly after one another, for example, on 3 days during 1 week. This could yield a reliable impression of the true minimum plasma level. Finally, assay variation should be considered as a factor of influence on the observed variability.

In conclusion, our study shows that mitotane plasma levels display short-term variability that is greater than expected and of clinical importance because random sampling could yield incidentally high levels. Mitotane levels may also increase during the day even when a morning dose is skipped. Previous research showed that mitotane plasma trough levels $\geq 14 \mathrm{mg} / \mathrm{l}$ are associated with a maximum therapeutic efficacy. For this reason, we recommend trough sampling as standard management in monitoring mitotane treatment. In order to prevent measurement of inappropriately high levels, early morning appears to be the most suitable moment to assess trough levels.

\section{Declaration of interest}

The authors declare that there is no conflict of interest that could be perceived as prejudicing the impartiality of the research reported.

\section{Funding}

This research did not receive any specific grant from any funding agency in the public, commercial, or not-for-profit sector.

\section{References}

1 Temple TE Jr, Jones DJ Jr, Liddle GW \& Dexter RN. Treatment of Cushing's disease. correction of hypercortisolism by o, $\mathrm{p}^{\prime} \mathrm{DDD}$ without induction of aldosterone deficiency. New England Journal of Medicine 1969281 801-805. (doi:10.1056/NEJM196910092811501)

2 Fassnacht M \& Allolio B. Clinical management of adrenocortical carcinoma. Best Practice \& Research. Clinical Endocrinology \& Metabolism 200923 273-289. (doi:10.1016/j.beem.2008.10.008)

3 Ghataore L, Chakraborti I, Aylwin SJ, Schulte KM, Dworakowska D, Coskeran P \& Taylor NF. Effects of mitotane treatment on human steroid metabolism: implications for patient management. Endocrine Connections 20121 37-47. (doi:10.1530/EC-12-0028)

4 Terzolo M, Baudin E, Ardito A, Kroiss M, Leboulleux S, Daffara F, Perotti P, Feelders RA, Devries JH, Zaggia B et al. Mitotane levels predict the outcome of patients with adrenocortical carcinoma treated adjuvantly following radical resection. European Journal of Endocrinology 2013169 263-270. (doi:10.1530/EJE-13-0242)

5 Terzolo M, Ardito A, Zaggia B, Laino F, Germano A, De Francia S, Daffara F \& Berruti A. Management of adjuvant mitotane therapy following resection of adrenal cancer. Endocrine 201242 521-525. (doi:10.1007/s12020-012-9719-7)

6 Terzolo M, Angeli A, Fassnacht M, Daffara F, Tauchmanova L, Conton PA, Rossetto R, Buci L, Sperone P, Grossrubatscher E et al. Adjuvant mitotane treatment for adrenocortical carcinoma. New England Journal of Medicine 2007356 2372-2380. (doi:10.1056/ NEJMoa063360)

7 Berruti A, Baudin E, Gelderblom H, Haak HR, Porpiglia F, Fassnacht M, Pentheroudakis $\mathrm{G} \&$ on behalf of the ESMO Guidelines Working Group. Adrenal cancer: ESMO clinical practice guidelines for diagnosis, treatment and follow-up. Annals of Oncology 201223 (suppl 7) vii131-vii138. (doi:10.1093/annonc/mds231)

8 Haak HR, Hermans J, van de Velde CJ, Lentjes EG, Goslings BM, Fleuren GJ \& Krans HM. Optimal treatment of adrenocortical carcinoma with mitotane: results in a consecutive series of 96 patients. British Journal of Cancer 199469 947-951. (doi:10.1038/bjc.1994.183)

9 Baudin E, Pellegriti G, Bonnay M, Penfornis A, Laplanche A, Vassal G \& Schlumberger M. Impact of monitoring plasma 1,1-dichlorodiphenildichloroethane $\left(\mathrm{o}, \mathrm{p}^{\prime} \mathrm{DDD}\right)$ levels on the treatment of patients with adrenocortical carcinoma. Cancer 200192 1385-1392. (doi:10.1002/ 1097-0142(20010915)92:6 < 1385::AID-CNCR1461>3.0.CO;2-2)

10 Hermsen IG, Fassnacht M, Terz M, Houterman S, den Hartigh J, Leboulleux S, Daffara F, Berruti A, Chadarevian R, Schlumberger M et al. Plasma concentrations of $\mathrm{o}, \mathrm{p}^{\prime} \mathrm{DDD}, \mathrm{o}, \mathrm{p}^{\prime} \mathrm{DDA}$, and $\mathrm{o}, \mathrm{p}^{\prime} \mathrm{DDE}$ as predictors of tumor response to mitotane in adrenocortical carcinoma: results of a retrospective ENS@T multicenter study. Endocrine 201196 1844-1851. (doi:10.1210/jc.2010-2676)

11 Mauclere-Denost S, Leboulleux S, Borget I, Paci A, Young J, Al Ghuzlan A, Deandreis D, Drouard L, Tabarin A, Chanson P et al. High-dose mitotane strategy in adrenocortical carcinoma: prospective analysis of plasma mitotane measurement during the first 3 months of follow-up. European Journal of Endocrinology 2012166 261-268. (doi:10.1530/EJE-11-0557)

12 Kerkhofs T, Baudin E, Terzolo M, Allolio B, Chadarevian R, Mueller H, Skogseid B, Leboulleux S, Mantero F, Haak H et al. Comparison of two mitotane starting dose regimens in patients with advanced adrenocortical carcinoma. Journal of Clinical Endocrinology and Metabolism 2013 98 4759-4767. (doi:10.1210/jc.2013-2281)

13 Kerkhofs T, Derijks L, Ettaieb M, den Hartigh J, Neef C, Gelderblom H, Guchelaar H \& Haak H. Development of a pharmacokinetic model of mitotane: towards personalized dosing in adrenocortical carcinoma. Therapeutic Drug Monitoring 2014 (In press).

14 Moolenaar AJ, van Slooten H, van Seters AP \& Smeenk D. Blood levels of $\mathrm{o}, \mathrm{p}^{\prime}$-DDD following administration in various vehicles after a single dose and during long-term treatment. Cancer Chemotherapy and Pharmacology 19817 51-54. (doi:10.1007/BF00258213)

15 Hermsen IG, den Hartigh J \& Haak HR. Mitotane serum level analysis; good agreement between two different assays. Clinical Endocrinology 201073 271-272. (doi:10.1111/j.1365-2265.2010.03787.x) 
16 Moy RH. Studies of the pharmacology of o, $\mathrm{p}^{\prime} \mathrm{DDD}$ in man. Journal of Laboratory and Clinical Medicine 196158 296-304.

17 Gebhardt DO, Moolenaar AJ, van Seters AP, van der Velde EA \& Gevers Leuven JA. The distribution of o,p'-DDD (mitotane) among serum lipoproteins in normo- and hypertriglyceridemia. Cancer Chemotherapy and Pharmacology 199229 331-334. (doi:10.1007/ BF00685956)

18 Cai W, Benitez R, Counsell RE, Djanegara T, Schteingart DE, Sinsheimer JE \& Wotring LL. Bovine adrenal cortex transformations of mitotane [1-(2-chlorophenyl)-1-(4-chlorophenyl)-2,2-dichloroethane; o,p'-DDD] and its p,p'- and m,p'-isomers. Biochemical Pharmacology 199549 1483-1489. (doi:10.1016/0006-2952(95) 00028-X)
19 von Slooten H, van Seters AP, Smeenk D \& Moolenaar AJ. O,p'-DDD (mitotane) levels in plasma and tissues during chemotherapy and at autopsy. Cancer Chemotherapy and Pharmacology 19829 85-88. (doi:10.1007/BF00265384)

20 D'Avolio A, De Francia S, Basile V, Cusato J, De Martino F, Pirro E, Piccione F, Ardito A, Zaggia B, Volante M et al. Influence of the CYP2B6 polymorphism on the pharmacokinetics of mitotane. Pharmacogenetics and Genomics 201323 293-300. (doi:10.1097/FPC.0b013e3283606cb2)

21 Daffara F, De Francia S, Reimondo G, Zaggia B, Aroasio E, Porpiglia F, Volante M, Termine A, Di Carlo F, Dogliotti L et al. Prospective evaluation of mitotane toxicity in adrenocortical cancer patients treated adjuvantly. Endocrine-Related Cancer 200815 1043-1053. (doi:10.1677/ERC-08-0103)

Received 14 May 2014

Revised 18 August 2014

Accepted 5 September 2014 